\title{
Virulence factors and antimicrobial resistance of uropathogenic Escherichia coli (UPEC) isolated from urinary tract infections: a systematic review and meta- analysis
}

Gabriel Kambale Bunduki ${ }^{1,2,3,4^{*}}$ (D) Eva Heinz ${ }^{5}$, Vincent Samuel Phiri ${ }^{6}$, Patrick Noah ${ }^{7}$, Nicholas Feasey ${ }^{3,5}$ and Janelisa Musaya ${ }^{1,3}$

\begin{abstract}
Background: Uropathogenic Escherichia coli (UPEC) are amongst the most frequent causes of urinary tract infections. We report a systematic review and meta-analysis of virulence factors and antimicrobial resistance of UPEC isolated from urinary tract infections.
\end{abstract}

Methods: A systematic review and meta-analysis were performed using PRISMA guidelines (Research Registry ref. 5874). Data were extracted from PubMed/MEDLINE and ScienceDirect databases for studies published from January 1, 2000 to December 31, 2019. Studies reporting antimicrobial resistance and virulence factors of UPEC isolated in confirmed urinary tract infections ( $\geq 10^{5} \mathrm{CFU} / \mathrm{ml}$ ) were eligible. Prevalence of antimicrobial resistance and virulence factors of UPEC were estimated using random-effects meta-analysis model. Estimates with 95\% confidence intervals, I-square $\left(I^{2}\right)$ statistic, and Cochran's $Q$ test were computed using the score statistic and the exact binomial method by incorporating the Freeman-Tukey double arcsine transformation of proportions.

Results: Our search returned 2504 hits, of which 13 studies were included in the meta-analysis, totalling 1888 UPEC isolates. Highest antimicrobial resistance rates were observed among the antibiotic class of tetracycline in $69.1 \%$ (498/721), followed by sulphonamides in 59.3\% (1119/1888), quinolones in 49.4\% (1956/3956), and beta-lactams in $36.9 \%$ (4410/11964). Among beta-lactams, high resistance was observed in aminopenicillins in $74.3 \%(1157 / 1557)$ and first generation cephalosporins in 38.8\% (370/953). Meanwhile, virulence factors with highest prevalence were immune suppressors (54.1\%) followed by adhesins (45.9\%). Taken individually, the most observed virulence genes were shiA (92.1\%), CSH (80.0\%), fimH/MSHA (75.3\%), traT (75.1\%), sisA (72.2\%), iuCD (65.7\%), iutA (61.8\%), kpsMTII (60.6\%), and PAl (55.2\%).

\footnotetext{
* Correspondence: gbunduki@mlw.mw

'Department of Pathology, Kamuzu University of Health Sciences (former College of Medicine/University of Malawi), Blantyre, Malawi

${ }^{2}$ Africa Centre of Excellence in Public Health and Herbal Medicine (ACEPHEM), Blantyre, Malawi

Full list of author information is available at the end of the article
}

(C) The Author(s). 2021 Open Access This article is licensed under a Creative Commons Attribution 4.0 International License, which permits use, sharing, adaptation, distribution and reproduction in any medium or format, as long as you give appropriate credit to the original author(s) and the source, provide a link to the Creative Commons licence, and indicate if changes were made. The images or other third party material in this article are included in the article's Creative Commons licence, unless indicated otherwise in a credit line to the material. If material is not included in the article's Creative Commons licence and your intended use is not permitted by statutory regulation or exceeds the permitted use, you will need to obtain permission directly from the copyright holder. To view a copy of this licence, visit http://creativecommons.org/licenses/by/4.0/ The Creative Commons Public Domain Dedication waiver (http://creativecommons.org/publicdomain/zero/1.0/) applies to the data made available in this article, unless otherwise stated in a credit line to the data. 
Conclusions: The increased antibiotic resistance of UPEC isolates was demonstrated and suggested a need for reassessment of empirical therapies in urinary tract infections treatment caused by this pathogen. In addition, this pathotype exhibited diverse surface and secreted virulence factors.

Keywords: Urinary tract infection, Escherichia coli, Virulence factors, Antimicrobial resistance, Systematic review, Meta-analysis

\section{Background}

Antimicrobial resistance (AMR) has increasingly been reported in bacteria causing urinary tract infections (UTI) during the last few decades and has become a major public health concern [1]. Globally the most common cause of UTI is Escherichia coli [2], a ubiquitous gram negative pathogen and member of the family $E n$ terobacteriaceae. Uropathogenic E. coli (UPEC) are among the most common extra-intestinal pathogenic $E$. coli (ExPEC) encountered [3]. E. coli typically acquires AMR genes through mobile genetic elements (MGE), such as plasmids, insertion sequences, transposons, and gene cassettes/integrons [4]. A large number of resistance-encoding mobile elements, in particular plasmids, are shared between different members of the Enterobacteriaceae and thus further promote the spread of resistance genes [5]. MGE can also encode for virulence factors, and there may be interplay between virulence and antimicrobial resistance [4].

E. coli is a commensal inhabitant of human and animal gastrointestinal tract and maintains the stability and homeostasis of luminal microbial flora by the symbiotic interplay with its hosts [6]. While confined in the intestinal lumen, this bacterium remains harmless in healthy individuals but some strains may cause diarrhoea in some circumstances. Meanwhile, several E. coli lineages have acquired specific virulence characteristics, giving them the capacity to thrive in specific niches and cause disease generally grouped in three clinical syndromes: enteric/diarrhoeal disease, urinary tract infections (UTIs) and sepsis/meningitis [7]. These virulence characteristics are often encoded on genetic elements that can be mobilized to establish new combinations of virulence factors in different strains, or on genetic elements that have once been mobile but now become fixed in the chromosome [7]. UPEC has large and small pathogenicity islands (PAIs), which are integrated mobile elements that encode for the key virulence factors. These allow UPEC to infect an immunocompetent host, as they encode for factors enabling it to colonize the periurethral area and ascend the urethra to the bladder [7].

Key virulence factors involved in the pathophysiology of UTIs function in invasion, colonization and mediation of host defences subversion [8]. PAIs furthermore often carry cryptic or functional genes that encode mobility factors, such as integrases, transposases and insertion sequence elements [7], which are traces from their mobile history and may promote and contribute to the spread and emergence of antimicrobial resistance [9-12].

Community and hospital acquired UTIs significantly affect the life quality of infected patients [13]. It has been reported that $E$. coli is expected to cause loss of lives of more than 3 million people each year by 2050 following the increase in multi-drug resistance. A particular focus is placed to track carbapenem-resistant strains which are spreading world-wide and only leave few last-line treatment options like colistin or tigecycline, which are known for severe side-effects and not applicable for all types of bacterial infections due to reduced tissue permeation, respectively; and resistance mechanisms against both of these are increasingly observed [14].

Here, we report a systematic review and meta-analysis of virulence factors and antimicrobial resistance of UPEC. We also briefly review the relationship between virulence factors and antimicrobial resistance.

\section{Methods}

The preferred reporting items for systematic reviews and meta-analyses (PRISMA) guidelines [15] were used in conducting this systematic review. The protocol of this review was registered in the Research Registry (ref 5874) (https://www.researchregistry.com/browse-theregistry\#home/registrationdetails/5f2bbf5e83bd1d001 $7 \mathrm{e} 9 \mathrm{ec} 9 \mathrm{e} /)$.

\section{Search strategy}

The electronic bibliographic databases PubMed/MEDLINE and ScienceDirect were searched in all fields with the search terms combined as follow: Virulence factors OR virulence AND factors OR virulence factors AND associated AND anti-infective agents OR anti-infective agents OR anti-infective AND agents OR anti-infective agents OR antimicrobial AND resistance AND uropathogenic Escherichia coli OR uropathogenic AND Escherichia AND coli OR uropathogenic Escherichia coli AND UPEC.

A 20 year time period, between 2000 and 2019, was considered for the search. This time limit was based on possible changes in the virulence, microbiology, epidemiology and antimicrobial susceptibility patterns of uropathogenic E. coli [16]. The number of records retrieved for each database searched was recorded. 
Reference lists of identified studies were checked manually to supplement the electronic search. Retrieved studies were exported into Mendeley Desktop version 1.19.4 and screened against inclusion and exclusion criteria.

\section{Inclusion and exclusion criteria}

Observational (cross sectional, prospective and retrospective cohort, and case-control) studies reporting the virulence and antimicrobial susceptibility patterns of uropathogenic $E$. coli isolated from human samples from patients of any age and region were included in this review. Studies published before 2000 and after 2019, and those reporting results from animal samples were excluded. Grey literature was not considered. Studies published in any other language than English and those with non-accessibility to full-texts were excluded. Only studies reporting their microbiologically confirmed UTI $\left(\geq 10^{5} \mathrm{CFU} / \mathrm{ml}\right)$ using the Centre of Disease Control and Prevention's definition were included in this review [17]. This review included both inpatients and outpatients with UTIs. Hence, data from a study which used both settings were considered as two separate studies and each was counted as a single study.

\section{Study selection}

The identified titles and abstracts of all the studies retrieved in the electronic databases and searched manually were screened for their appropriateness and relevance to the main aim of the systematic review. Studies that were irrelevant were excluded at this stage. Full texts of potentially relevant studies were downloaded and added to a created Mendeley library and were assessed for inclusion and exclusion criteria of this systematic review. Quality and risk bias assessment was done for included studies containing relevant data for the systematic review and meta-analysis.

The author GKB performed the selection process and other stages of this review. Ten percent of identified studies were screened independently for inclusion and exclusion criteria by JM at each stage of the review. The discrepancies in either the decision on inclusion or exclusion of studies, quality assessment or on data extraction were discussed between GKB and JM to make the consensus for the final decision.

\section{Data extraction}

Data extraction was independently done by GKB and JM and was compared for matching. For variables with missing information or with disagreement between the two authors, a consensus between the authors was made for the final decision.

An Excel 2010 spreadsheet was used for data extraction and contained the following data for studies that met inclusion criteria: first author, year of publication, country/place of study, study population/sample size, patient types (inpatients or outpatients), prevalence of antimicrobial resistance of different antibiotics tested, method used for detecting virulence factors, and prevalence of virulence factors.

\section{Quality assessment and risk of bias in individual studies} The Newcastle-Ottawa Scale (NOS) adapted for crosssectional studies was used for assessing the risk of bias of included studies (Supplemental file 1). This scale was adapted from the NOS quality assessment scale for cohort studies. The assessment was in the area of selection (maximum of 3 points), comparability (maximum of 2 points) and outcome (maximum of 3 points). This was done by GKB and JM. Studies were classified into 4 categories: very good (9-10 points), good (7-8 points), satisfactory (5-6 points) and unsatisfactory ( $0-4$ points). The complete assessment of studies is found in the supplemental file 2 .

\section{Statistical analysis}

We used metaprop and metaprop_one commands in Stata 16 for Windows to conduct the meta-analysis. Prevalence of antimicrobial resistance and virulence factors of UPEC were estimated using random-effects meta-analysis model. The 95\% Wald confidence intervals were computed using the score statistic and the exact binomial method by incorporating the Freeman-Tukey double arcsine transformation of proportions for avoiding exclusion of studies with proportion equal to 0 or 1 from the calculation of the estimate [18]. The effect size of the prevalence was considered statistically significant when $p$-value was $<0.05$. The proportions with $95 \%$ Wald confidence intervals were generated. I-square $\left(I^{2}\right)$ statistic test was used to evaluate the proportion of statistical heterogeneity and the Cochran's Q test was used to explain the degree of heterogeneity. The funnel plot publication bias was not assessed as it is not relevant for the prevalence studies [19], however, the Egger's linear regression test was used.

\section{Results \\ Study selection}

The literature search using PRISMA identified a total of 2536 studies (2504 studies through databases searching and 32 from other sources). After removing duplicates, 1053 were screened for eligibility. After the screening of titles and abstracts, 1006 studies were excluded. Fulltexts of the remaining 47 studies were read and 35 more studies were excluded. At the end, 12 papers were included; from which 14 studies were included in the qualitative analysis and 13 in the meta-analysis as explained below (Fig. 1). 


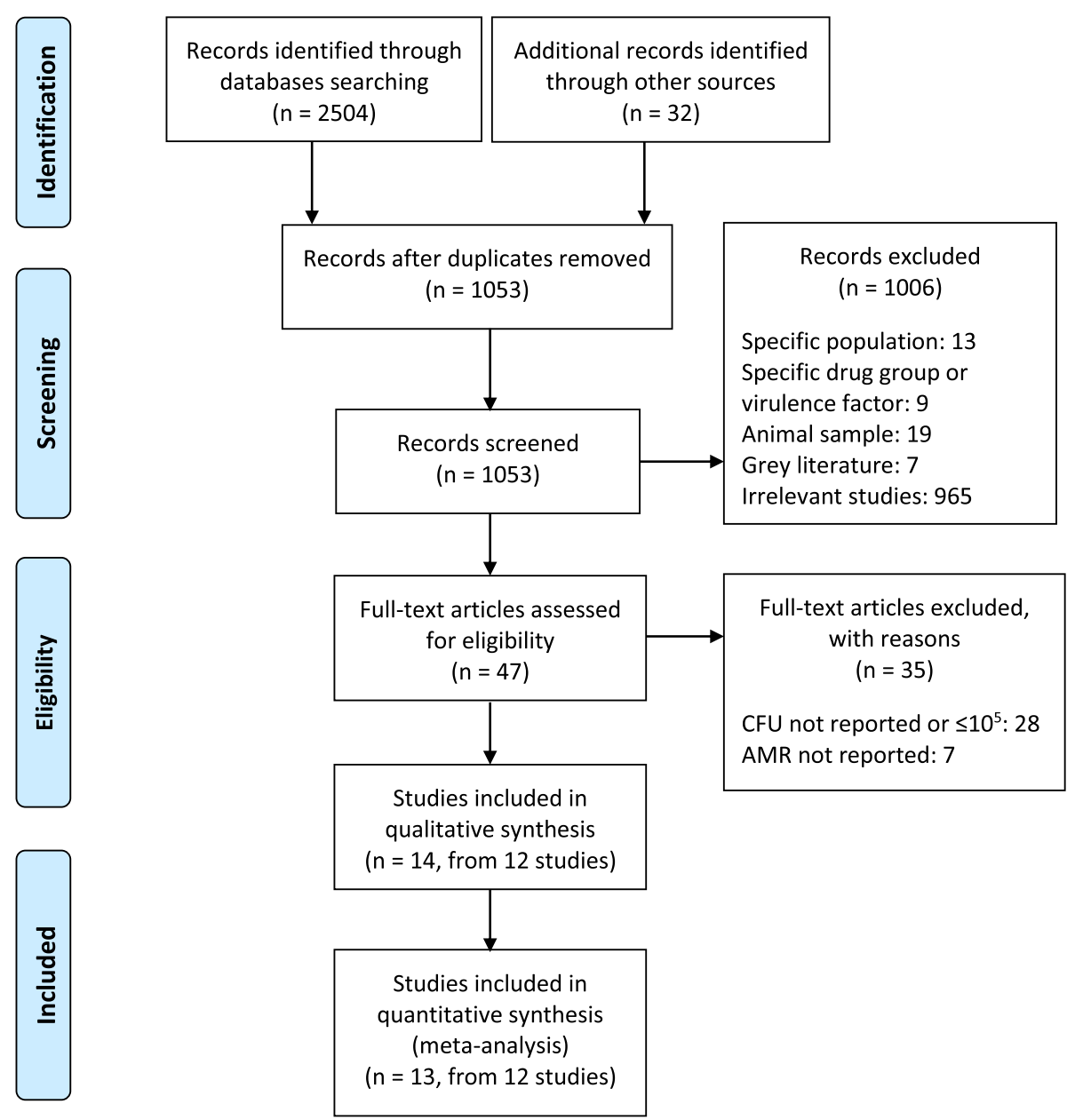

Fig. 1 The PRISMA flowchart for literature search and study selection

\section{Study characteristics}

Study characteristics of included studies are presented in Table 1 . The 14 studies reported in this systematic review represent 8 countries, namely Iran (6 studies), China (2), India (1), Poland (1), Jordan (1), Mexico (1), Brazil (1) and Nigeria (1). The total sample size of UPEC isolates from the 14 studies is 1888 (range 32-227). Nine of the 14 studies report UPEC from inpatients [2, 20-23, $25,27,29,30]$ while 5 are from outpatients $[20,24,26$, 28, 30]. Among the 14 studies, 2 studies reported UPEC from in- and out-patients $[20,30]$ and were therefore considered each as single study for each category of patients. Meanwhile, 2 other studies [26, 27] reported UPEC in in- and out-patients but did not specify sample size in each category of patients. After consensus of authors, one was considered as reporting in-patients [27] and another one out-patients [26]. Among the 13 studies included in the meta-analysis, one reported in- and outpatient UPEC but did not distinguish the two categories while reporting the antimicrobial resistance rate [20], and was hence considered as a single study in the metaanalysis.

Of the 14 included studies, 9 studies used the polymerization chain reaction (PCR) as method for detecting virulence factors of UPEC [2, 20, 22-26, 28, 30], 3 studies used phenotypical methods [21, 27, 29], while 2 studies used both methods [22, 24].

\section{Quality assessment and bias assessment}

Based on the quality assessment of studies using the NOS assessment, six studies scored 8 points [20, 23, 24, $26,29,30]$, which could be regarded as good studies. While eight studies scored 5-6 points [2, 20-22, 25, 27, $28,30]$, and could be regarded as satisfactory studies. The detailed NOS assessment is found in the supplemental file 2. A bias assessment was done on the countries of origin of the included studies. The Egger's regression intercept was of -7.71 , with a standard error of 2.23, 95\% CI: $-2.26-3.46, \mathrm{t}$-value of 6.0 and $p=$ 0.013 . The fact that almost $50 \%$ of included studies in 
Table 1 Characteristics of included studies after full assessment

\begin{tabular}{lllllll}
\hline Authors & Publication year & Country & Sample size & Type of patients & Method for VFs detection & NOS points \\
\hline Ghazvini et al. (1) [20] & 2019 & Iran & 168 & Outpatients & PCR & PCR \\
Ghazvini et al. (2) [20] & 2019 & Iran & 32 & Inpatients & Inpatients & Phenotypical \\
Jadhav et al. [21] & 2011 & India & 150 & Inpatients & Phenotypical, PCR \\
Kot et al. [22] & 2016 & Poland & 173 & Inpatients & PCR \\
Malekzadegan et al. [23] & 2018 & Iran & 126 & Outpatients & Phenotypical, PCR \\
Miranda-Estrada et al. [24] & 2017 & Mexico & 107 & Inpatients & PCR & 6 \\
Neamati et al. [25] & 2015 & Iran & 150 & Outpatients & PCR & 8 \\
Oliveira et al. [26] & 2011 & Brazil & 204 & Inpatients & Phenotypical \\
Olorunmola et al. [27] & 2013 & Nigeria & 137 & Inpatients & PCR \\
Raeispour et al. [2] & 2018 & Iran & 60 & Outpatients & PCR \\
Shakhatreh et al. [28] & 2019 & Jordan & 227 & Inpatients & Phenotypical \\
Tabasi et al. [29] & 2015 & Iran & 156 & Inpatients & PCR \\
Wang et al. (1) [30] & 2014 & China & 69 & Outpatients & PCR \\
Wang et al. (2) [30] & 2014 & China & 129 & & 5 \\
\hline
\end{tabular}

this meta-analysis came from a single country could have introduced a bias in the analysis.

\section{Antimicrobial resistance and virulence factors of UPEC}

Of the 13 studies included in the meta-analysis, the pooled number of $E$. coli isolates was 1888 . Tables 2 and 3 both present the specific proportions of antimicrobial resistance and virulence factors with $95 \%$ exact confidence intervals for each antibiotic and virulence factor, and the $I^{2}$ and Q statistics which describe proportions of total variations due to inter-antibiotics/virulence factors heterogeneities. The heterogeneity tests for both antimicrobial resistance and virulence factors were significant $\left(I^{2}>75 \%\right)$. Highest antimicrobial resistance rates were observed among the antibiotic class of tetracyclines in 69.1\% (498/721) followed by sulphonamides in 59.3\% (1119/1888), quinolones in 49.4\% (1956/3956), beta-lactams in 36.9\% (4410/ $11964)$, aminoglycosides in $28.7 \%$ (881/3069), nitrofurans in $20.0 \%(297 / 1486)$ and fosfomycin in $8.4 \%(9 / 107)$ (Fig. 2a). Among beta-lactams, high resistance was observed in aminopenicillins in $74.3 \%(1157 / 1557)$, betalactam associated with inhibitors in 39.0\% (604/1550), cephalosporins in $35.8 \%(2564 / 7155)$ and monobactam in $22.0 \%(78 / 354)$. However, carbapenems had the least rate of resistance, $0.5 \%$ (7/1348) (Fig. 2b). Among the cephalosporins, high rates of resistance were observed in the first generation cephalosporins in $38.8 \%$ (370/953) and third generation cephalosporins in $37.0 \%$ (1421/3838) (Fig. 2c). While taken individually, the highest resistance was observed in the following antibiotics: ampicillin 75.0\% (835/ 1114, 95\% CI: 0.72-0.77), amoxicillin 72.7\% (322/443, 95\% CI: 0.68-0.77), tetracycline 69.1\% (498/721, 95\% CI: 0.66$0.72)$, cotrimoxazole $59.3 \%$ (1119/1888, 95\% CI: $0.57-$ 0.61), nalidixic acid 59.0\% (777/1317, 95\% $0.56-0.62)$, cefpodoxime 57.8\% (166/287, 95\% CI: 0.52-0.63), cephalexin 56.6\% (146/258, 95\% CI: 0.50-0.63), and cefuroxime 55.2\% (389/705, 95\% CI: 0.51-0.59). Meanwhile, virtually almost all isolates were susceptible to the carbapenems with the following resistance rates: ertapenem in $0.4 \%$ (1/ 227, 95\% CI: $0.00-0.03)$, imipenem 0.7\% (5/567, 95\% CI: $0.00-0.02)$, and meropenem in $0.3 \%$ (1/354, $95 \%$ CI: 0.00 0.02) (Table 2).

Regarding the virulence factors, both factors associated with $E$. coli surface cell and those secreted and exported to the site of action were observed. Taking into account the groups of virulence factors according to their action mechanisms, a high prevalence was observed among immune suppressors in $54.1 \%(874 / 1615)$, followed by adhesins in $45.9 \%(2316 / 5048)$, siderophore systems in 41.8\% (647/1549) and toxins in 19.9\% (529/2664) (Fig. $2 \mathrm{~d})$. Taken individually, the most prevalent virulence factors from adhesins group were: the cell surface hydrophobicity $(\mathrm{CSH})$ in $80 \%$ (120/150, 95\% CI: 0.73-0.86), the fimbrial and afimbrial adhesins: fimH/MSHA in 75.3\% (881/1170, 95\% CI: 0.73-0.78), fimP/MRHA in $35.6 \%$ (219/616, 95\% CI: 0.32-0.39), the serum resistance coded by the gene $\operatorname{traT}$ in $75.1 \%(266 / 354,95 \% \mathrm{CI}$ : $0.70-0.79)$, the capsular polysaccharide $\mathrm{K}$ antigen (kpsMTII) in 60.6\% (120/198, 95\% CI: 0.54-0.67) and pap in $30.2 \%$ (350/1158, 95\% CI: 0.28-0.33). Frequencies of immune suppressors coded by the pathogenicity islands (PAIs) genes were shiA in $92.1 \%(209 / 227,95 \%$ CI: $0.88-0.95)$, sis A in $72.2 \%$ (164/227, 95\% CI: $0.66-$ $0.78)$, sisB in $24.7 \%$ (56/227, 95\% CI: $0.19-0.31)$ and $P A I$ in $55.2 \%(265 / 480,95 \%$ CI: $0.51-0.60)$. The secreted virulence factors exported to the site of infection were represented by toxins and siderophore molecules. The most frequent toxins observed were the haemolysin 
Table 2 Meta-analysis of antibiotic resistance for UPEC isolates from urinary tract infections

\begin{tabular}{|c|c|c|c|c|c|c|c|c|c|}
\hline \multirow[t]{2}{*}{ Antibiotics } & \multirow{2}{*}{$\begin{array}{l}\text { No of } \\
\text { studies }\end{array}$} & \multirow[t]{2}{*}{$n / N$} & \multicolumn{2}{|l|}{ Random model } & \multicolumn{2}{|c|}{ Heterogeneity } & \multicolumn{3}{|c|}{ Egger's test } \\
\hline & & & $\%(95 \% \mathrm{Cl})$ & $\mathbf{P}$ & $\bar{Q}$ & $\mathbf{P}$ & $\overline{1^{2}}$ & $\mathrm{t}$ & $P$ \\
\hline Amikacin & 8 & $214 / 1074$ & $19.9(0.18-0.22)$ & $<0.001$ & 344.4 & $<0.001$ & 96.5 & 3.98 & 0.002 \\
\hline Amoxicillin & 3 & $322 / 443$ & $72.7(0.68-0.77)$ & $<0.001$ & 225.6 & $<0.001$ & 94.7 & 4.76 & 0.001 \\
\hline Amoxiclav & 6 & 407/998 & $40.8(0.38-0.44)$ & $<0.001$ & 406.2 & $<0.001$ & 97.1 & 2.35 & 0.039 \\
\hline Ampicillin & 8 & $835 / 1114$ & $75.0(0.72-0.77)$ & $<0.001$ & 222.9 & $<0.001$ & 94.6 & 1.15 & 0.276 \\
\hline Ampicillin-sulbactam & 3 & $161 / 354$ & $45.5(0.40-0.51)$ & 0.089 & 178.0 & $<0.001$ & 93.3 & 5.54 & $<0.001$ \\
\hline Aztreonam & 2 & $78 / 354$ & $22.0(0.18-0.27)$ & $<0.001$ & 172.8 & $<0.001$ & 93.1 & 24.1 & $<0.001$ \\
\hline Cefepime & 7 & 280/952 & $29.4(0.27-0.32)$ & $<0.001$ & 143.3 & $<0.001$ & 91.6 & 3.38 & 0.006 \\
\hline Cefixime & 3 & $120 / 443$ & $27.1(0.23-0.31)$ & $<0.001$ & 124.0 & $<0.001$ & 90.3 & 5.58 & 0.001 \\
\hline Cefoperazone-sulbactam & 2 & $36 / 198$ & $18.2(0.13-0.24)$ & $<0.001$ & 81.21 & $<0.001$ & 85.2 & 24.2 & $<0.001$ \\
\hline Cefotaxime & 7 & $379 / 1055$ & $35.9(0.33-0.39)$ & $<0.001$ & 235.5 & $<0.001$ & 94.9 & 3.99 & 0.002 \\
\hline Cefoxitin & 4 & 104/707 & $14.7(0.12-0.18)$ & $<0.001$ & 91.61 & $<0.001$ & 86.9 & 13.6 & $<0.001$ \\
\hline Cefpodoxime & 2 & $166 / 287$ & $57.8(0.52-0.63)$ & 0.008 & 182.7 & $<0.001$ & 93.4 & 11.5 & $<0.001$ \\
\hline Ceftazidime & 9 & $509 / 1209$ & $42.1(0.39-0.45)$ & $<0.001$ & 212.1 & $<0.001$ & 94.3 & 3.33 & 0.007 \\
\hline Ceftriaxone & 5 & $247 / 844$ & $29.3(0.26-0.32)$ & $<0.001$ & 239.6 & $<0.001$ & 95.0 & 5.50 & $<0.001$ \\
\hline Cefuroxime & 5 & $389 / 705$ & $55.2(0.51-0.59)$ & 0.006 & 288.2 & $<0.001$ & 95.8 & 3.16 & 0.009 \\
\hline Cephalexin & 3 & $146 / 258$ & $56.6(0.50-0.63)$ & 0.035 & 189.3 & $<0.001$ & 93.7 & 12.8 & $<0.001$ \\
\hline Cephalothin & 3 & $82 / 437$ & $18.8(0.15-0.23)$ & $<0.001$ & 181.0 & $<0.001$ & 93.4 & 3.23 & 0.008 \\
\hline Cephazolin & 3 & $142 / 258$ & $55.0(0.49-0.61)$ & 0.106 & 168.4 & $<0.001$ & 92.9 & 13.7 & $<0.001$ \\
\hline Ciprofloxacin & 12 & 792/1781 & $44.5(0.42-0.47)$ & $<0.001$ & 265.5 & $<0.001$ & 95.5 & 0.54 & 0.602 \\
\hline Ertapenem & 1 & $1 / 227$ & $0.4(0.00-0.03)$ & $<0.001$ & 0.799 & 1.000 & 0.00 & 0.49 & 0.634 \\
\hline Fosfomycin & 1 & $9 / 107$ & $8.4(0.04-0.15)$ & $<0.001$ & 37.35 & $<0.001$ & 67.9 & 21.0 & $<0.001$ \\
\hline Gentamicin & 13 & 637/1888 & $33.7(0.32-0.36)$ & $<0.001$ & 269.6 & $<0.001$ & 95.6 & 0.70 & 0.497 \\
\hline Imipenem & 7 & $5 / 767$ & $0.7(0.00-0.02)$ & $<0.001$ & 3.719 & 0.988 & 0.00 & 5.02 & $<0.001$ \\
\hline Meropenem & 3 & $1 / 354$ & $0.3(0.00-0.02)$ & $<0.001$ & 1.416 & 1.000 & 0.00 & 2.40 & 0.035 \\
\hline Nalidixic acid & 9 & $777 / 1317$ & $59.0(0.56-0.62)$ & $<0.001$ & 248.2 & $<0.001$ & 95.2 & 1.70 & 0.118 \\
\hline Nitrofurantoin & 10 & 297/1486 & $20.0(0.18-0.22)$ & $<0.001$ & 297.1 & $<0.001$ & 96.0 & 3.77 & 0.003 \\
\hline Norfloxacin & 5 & $286 / 614$ & $46.6(0.43-0.51)$ & 0.090 & 273.1 & $<0.001$ & 95.6 & 3.20 & 0.009 \\
\hline Ofloxacin & 2 & $101 / 244$ & $41.4(0.35-0.48)$ & 0.007 & 153.5 & $<0.001$ & 92.2 & 13.6 & $<0.001$ \\
\hline Tetracycline & 6 & $498 / 721$ & $69.1(0.66-0.72)$ & $<0.001$ & 207.3 & $<0.001$ & 94.2 & 2.44 & 0.033 \\
\hline Tobramycin & 1 & $30 / 107$ & $28.0(0.20-0.37)$ & $<0.001$ & 103.8 & $<0.001$ & 88.4 & 35.2 & $<0.001$ \\
\hline Co-trimoxazole & 13 & $1119 / 1888$ & $59.3(0.57-0.61)$ & $<0.001$ & 177.1 & $<0.001$ & 93.2 & 1.06 & 0.313 \\
\hline
\end{tabular}

$(h l y A)$ in $22.1 \%(334 / 1511,95 \%$ CI: $0.20-0.24)$, the secreted autotransporter toxin (sat) in $26.2 \%(28 / 107,95 \%$ CI: $0.19-0.35)$ and the cytotoxic necrotizing factor-1 (cnf-1) in 13.3\% (91/682, 95\% CI: 0.11-0.16). For siderophores, the aerobactin system was observed most frequently, and included outer membrane proteins genes: iucD in $65.7 \%$ (95\% CI: 0.59-0.72), iutA in 61.8\% (0.55$0.68)$, the aerobactin (aer) in $52.4 \%(130 / 198,95 \% \mathrm{CI}$ : $0.48-0.57)$ and the heme receptor genes (chuA) in $20.3 \%$ (46/227, 95\% CI: 0.16-0.26) (Table 3). High rates of AMR and virulence factors are statistically significant among in-patients than in out-patients as shown in Table 4.

\section{Relationship between antimicrobial resistance and virulence factors in UPEC}

In this section, we will briefly review the possible relation between AMR and virulence factors in UPEC on selected examples, focusing on resistance to quinolones and beta-lactams. We will discuss how harbouring virulence factors may increase or decrease the possibility of UPEC to develop resistance to antibiotics, although only aggregate data were available and trends in AMR and virulence factor carriage could not be directly related in this analysis.

Previous studies on UPEC reported that quinoloneresistant isolates encoded for virulence factor genes 
Table 3 Meta-analysis of virulence factors for UPEC isolates from urinary tract infections

\begin{tabular}{|c|c|c|c|c|c|c|c|c|c|}
\hline \multirow[t]{2}{*}{ Antibiotics } & \multirow{2}{*}{$\begin{array}{l}\text { No of } \\
\text { studies }\end{array}$} & \multirow[t]{2}{*}{$n / N$} & \multicolumn{2}{|l|}{ Random model } & \multicolumn{2}{|c|}{ Heterogeneity } & \multicolumn{3}{|c|}{ Egger's test } \\
\hline & & & $\%(95 \% \mathrm{Cl})$ & $P$ & $\bar{Q}$ & $P$ & $\overline{1^{2}}$ & $\mathrm{t}$ & $P$ \\
\hline aer & 3 & 229/437 & $52.4(0.48-0.57)$ & 0.315 & 189.2 & $<0.001$ & 93.1 & 4.45 & 0.001 \\
\hline$a f a$ & 5 & $98 / 701$ & $14.0(0.12-0.17)$ & $<0.001$ & 169.6 & $<0.001$ & 92.3 & 4.54 & 0.001 \\
\hline chuA & 1 & $46 / 227$ & $20.3(0.16-0.26)$ & $<0.001$ & 93.10 & $<0.001$ & 86.0 & 25.9 & $<0.001$ \\
\hline cnfl & 5 & $91 / 682$ & $13.3(0.11-0.16)$ & $<0.001$ & 71.34 & $<0.001$ & 81.8 & 13.2 & $<0.001$ \\
\hline Colicin & 1 & $13 / 137$ & $9.5(0.06-0.16)$ & $<0.001$ & 45.42 & $<0.001$ & 71.4 & 16.9 & $<0.001$ \\
\hline $\mathrm{CSH}$ & 1 & $120 / 150$ & $80.0(0.73-0.86)$ & $<0.001$ & 242.1 & $<0.001$ & 94.6 & 39.3 & $<0.001$ \\
\hline eco274 & 1 & $99 / 227$ & $43.6(0.37-0.50)$ & 0.055 & 157.9 & $<0.001$ & 91.8 & 33.7 & $<0.001$ \\
\hline $\mathrm{fimH} / \mathrm{MSHA}$ & 10 & $881 / 1170$ & $75.3(0.73-0.78)$ & $<0.001$ & 210.7 & $<0.001$ & 93.8 & 0.72 & 0.489 \\
\hline fimP/MRHA & 4 & $219 / 616$ & $35.6(0.32-0.39)$ & $<0.001$ & 152.0 & $<0.001$ & 91.5 & 8.02 & $<0.001$ \\
\hline fyuA & 1 & $41 / 227$ & $18.1(0.14-0.24)$ & $<0.001$ & 85.68 & $<0.001$ & 84.8 & 24.8 & $<0.001$ \\
\hline hlyA & 12 & $334 / 1511$ & $22.1(0.20-0.24)$ & $<0.001$ & 241.9 & $<0.001$ & 94.6 & 2.62 & 0.022 \\
\hline$i u C D$ & 2 & 130/198 & $65.7(0.59-0.72)$ & $<0.001$ & 203.3 & $<0.001$ & 93.6 & 29.9 & $<0.001$ \\
\hline iutA & 2 & $144 / 233$ & $61.8(0.55-0.68)$ & $<0.001$ & 198.6 & $<0.001$ & 93.5 & 18.9 & $<0.001$ \\
\hline kpsMTII & 2 & $120 / 198$ & $60.6(0.54-0.67)$ & 0.003 & 191.2 & $<0.001$ & 93.2 & 36.4 & $<0.001$ \\
\hline PAl & 3 & $265 / 480$ & $55.2(0.51-0.60)$ & 0.023 & 241.8 & $<0.001$ & 94.6 & 3.80 & 0.003 \\
\hline pap & 9 & $350 / 1158$ & $30.2(0.28-0.33)$ & $<0.001$ & 87.35 & $<0.001$ & 98.9 & 0.54 & $<0.001$ \\
\hline sat & 1 & 28/107 & $26.2(0.19-0.35)$ & $<0.001$ & 100.3 & $<0.001$ & 87.0 & 25.3 & $<0.001$ \\
\hline sfa & 5 & $262 / 701$ & $37.4(0.34-0.41)$ & $<0.001$ & 10.08 & $<0.001$ & 90.8 & 0.05 & 0.001 \\
\hline shiA & 1 & 209/227 & $92.1(0.88-0.95)$ & $<0.001$ & 292.1 & $<0.001$ & 95.6 & 45.4 & $<0.001$ \\
\hline sis $A$ & 1 & $164 / 227$ & $72.2(0.66-0.78)$ & $<0.001$ & 234.0 & $<0.001$ & 94.5 & 40.9 & $<0.001$ \\
\hline $\operatorname{sis} B$ & 1 & $56 / 227$ & $24.7(0.19-0.31)$ & $<0.001$ & 106.9 & $<0.001$ & 89.8 & 27.8 & $<0.001$ \\
\hline $\operatorname{sivH}$ & 1 & $81 / 227$ & $35.7(0.30-0.42)$ & $<0.001$ & 137.5 & $<0.001$ & 90.6 & 31.5 & $<0.001$ \\
\hline trat & 2 & $266 / 354$ & $75.1(0.70-0.79)$ & $<0.001$ & 236.2 & $<0.001$ & 94.5 & 40.7 & $<0.001$ \\
\hline vat & 1 & $63 / 227$ & $27.8(0.22-0.34)$ & $<0.001$ & 115.9 & $<0.001$ & 88.8 & 28.9 & $<0.001$ \\
\hline$y f c v$ & 1 & $57 / 227$ & $25.1(0.20-0.31)$ & $<0.001$ & 108.2 & $<0.001$ & 88.0 & 27.9 & $<0.001$ \\
\hline
\end{tabular}

related to their ability to invade the urinary tract [31]. The relevant virulence factors, like haemolysin, aerobactin, cytotoxic necrotizing factor-1 (cnf-1) and sat are chromosomally encoded in the PAIs, which can be deleted from the chromosome spontaneously and easily [32, 33]. Quinolones can act by increasing the deletion and transposition of DNA regions during the development of quinolone-resistance facilitated by an exposure to quinolones [34]. While PAIs share some characteristics with bacteriophages, it has been proven that prophages hidden within chromosomal DNA are excised by the activation of SOS [35], a DNA repair mechanism. Quinolones likely contribute to the partial or total excision of PAIs in a SOS-dependent way because the antimicrobial agents activate the SOS system [36]. Hence, this may induce the loss of virulence factors of quinolone-resistant $E$. coli that are less able to cause invasive UTIs as this phenomenon may result in phenotypic changes in bacteria. Nevertheless, the fact that quinolone-resistance impairs the ability of UPEC to invade local tissue of the kidney and prostate does not disrupt a strain's capacity to cause bacteraemia (urosepsis) once local invasion has taken place [31].

In $E$. coli, the majority of virulence associated plasmids belong to the $\mathrm{F}$ incompatibility group and are often key determinants of antimicrobial resistance [37]. It is conceivable that genetic determinants of virulence may be co-mobilized under antimicrobial selective pressure if they are located on the same genetic platform as antimicrobial resistance genes (plasmids, transposons, integrons) [38]. The relationship between resistance and virulence remains uncertain and depends on the interaction between the strain's phylogenetic group and the type of resistance determinant [39]. In Enterobactericeae, the IncF plasmid family is very widespread and can encode aerobactin as well as other factors of putative virulence such as the $\operatorname{tra} T$ virulence protein, responsible for serum resistance in E. coli. Extended-spectrum beta- 
A

\begin{tabular}{|c|c|c|c|c|c|c|}
\hline \multirow[t]{2}{*}{ Antibiotic groups } & \multicolumn{6}{|c|}{ Statistics for each study } \\
\hline & $\begin{array}{l}\text { Event } \\
\text { rate }\end{array}$ & $\begin{array}{c}\text { Lower } \\
\text { limit }\end{array}$ & $\begin{array}{l}\text { Upper } \\
\text { limit } Z\end{array}$ & Z-Value $p$ & -Value & Total \\
\hline Aminoglycosides & 0.287 & 0.271 & $0.303-2$ & -22.798 & 0.000 & $881 / 3069$ \\
\hline Sulfonamides & 0.593 & 0.570 & 0.615 & 8.008 & 0.000 & $1119 / 1888$ \\
\hline Cyclines & 0.691 & 0.656 & 0.723 & 9.971 & 0.000 & $498 / 721$ \\
\hline Fosfomycin & 0.084 & 0.044 & 0.154 & -6.855 & 0.000 & $9 / 107$ \\
\hline Nitrofurans & 0.200 & 0.180 & $0.221-2$ & -21.383 & 0.000 & $297 / 1486$ \\
\hline Quinolones & 0.494 & 0.479 & 0.510 & -0.700 & 0.484 & $1956 / 3956$ \\
\hline Beta-lactams & 0.369 & 0.360 & $0.377-2$ & -28.400 & 0.000 & $4410 / 11964$ \\
\hline
\end{tabular}

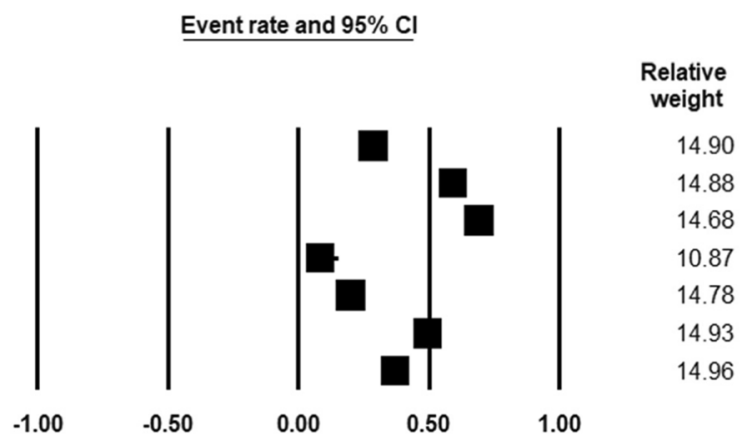

B

\begin{tabular}{lccccccc} 
Antibiotic groups & \multicolumn{6}{c}{ Statistics for each study } & \\
\cline { 3 - 6 } & & $\begin{array}{c}\text { Event } \\
\text { rate }\end{array}$ & $\begin{array}{c}\text { Lower } \\
\text { limit }\end{array}$ & $\begin{array}{c}\text { Upper } \\
\text { limit }\end{array}$ & z-Value & p-Value & Total \\
Aminopenicillins & 0.743 & 0.721 & 0.764 & 18.312 & 0.000 & $1157 / 1557$ \\
Carbapenems & 0.005 & 0.002 & 0.011 & -13.868 & 0.000 & $7 / 1348$ \\
Monobactams & 0.220 & 0.180 & 0.267 & -9.855 & 0.000 & $78 / 354$ \\
Beta-lactams+Inhibitors & 0.390 & 0.366 & 0.414 & -8.614 & 0.000 & $604 / 1550$ \\
Cephalosporins & 0.358 & 0.347 & 0.370 & -23.628 & 0.000 & $2564 / 7155$
\end{tabular}

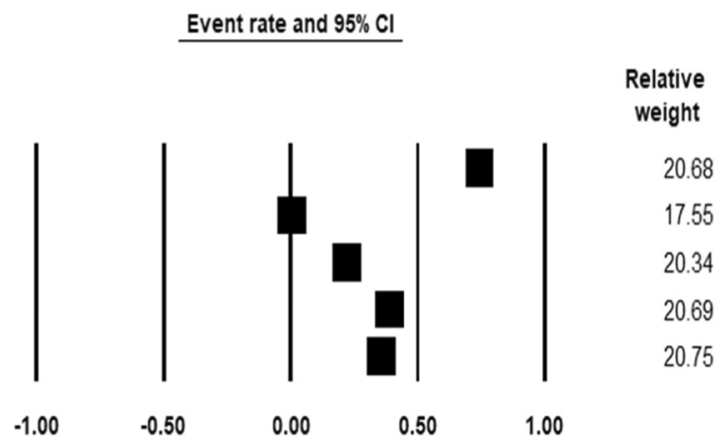

C

Antibiotic groups

Statistics for each study

Event rate and $95 \% \mathrm{Cl}$

$\begin{array}{lccccccc} & \begin{array}{c}\text { Event } \\ \text { rate }\end{array} & \begin{array}{c}\text { Lower } \\ \text { limit }\end{array} & \begin{array}{c}\text { Upper } \\ \text { limit }\end{array} & \text { Z-Value } & \text { p-Value } & \text { Total } \\ \text { 1GCs } & 0.388 & 0.358 & 0.420 & -6.841 & 0.000 & 370 / 953 \\ 2 G C s & 0.349 & 0.325 & 0.374 & -11.156 & 0.000 & 493 / 1412 \\ 3 G C s & 0.370 & 0.355 & 0.386 & -15.890 & 0.000 & 1421 / 3838 \\ 4 G C s & 0.294 & 0.266 & 0.324 & -12.308 & 0.000 & 280 / 952\end{array}$

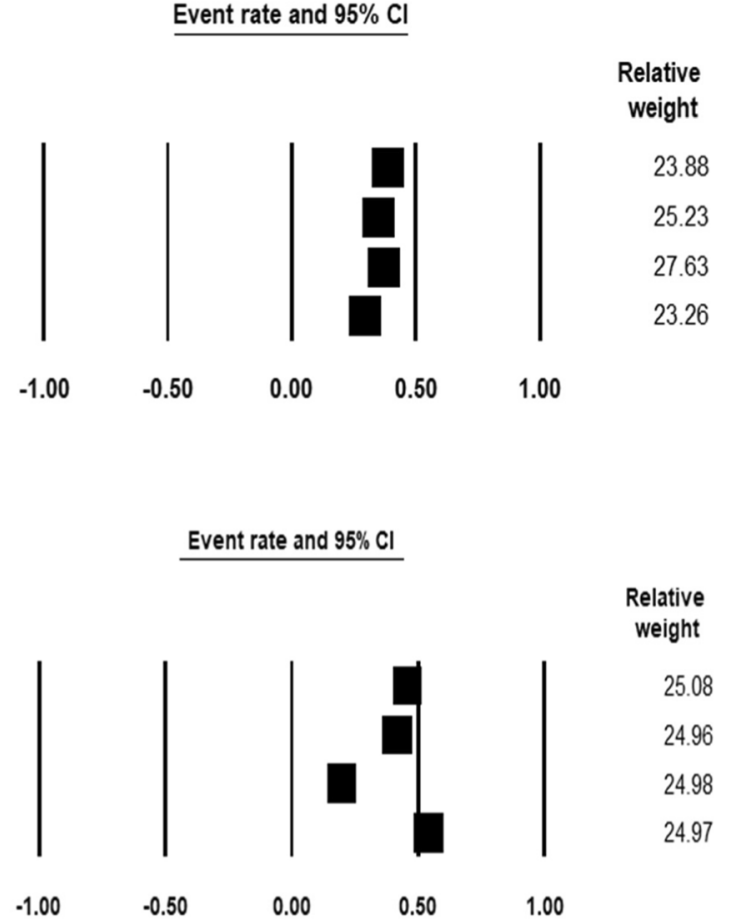

Fig. 2 Forest plot of UPEC resistance to different antibiotic subgroups (A main antibiotic groups, B Beta-lactams classes, C Cephalosporins classes) and virulence factors groups (D) 
Table 4 Distribution of antibiotics resistance and virulence factors among in- and out-patients

\begin{tabular}{|c|c|c|c|c|}
\hline & In-patient, n/N (\%) & Out-patient, n/N (\%) & OR $(95 \% \mathrm{CI})$ & $p$-value \\
\hline \multicolumn{5}{|l|}{ A. Main antibiotic groups } \\
\hline Aminoglycosides & 403/1432 (28.1) & 478/1637 (29.2) & $0.96(0.83-1.12)$ & 0.631 \\
\hline Sulfonamides & 610/1021 (59.7) & $509 / 867(58.7)$ & $1.02(0.88-1.18)$ & 0.817 \\
\hline Cyclines & $416 / 614(67.8)$ & 82/107 (76.6) & $0.88(0.65-1.21)$ & 0.441 \\
\hline Fosfomycin & 0 & 9/107 (8.4) & $11.3(0.21-603.0)$ & 0.232 \\
\hline Nitrofurans & 130/952 (13.7) & 167/534 (31.3) & $0.44(0.34-0.56)$ & $<0.0001$ \\
\hline Quinolones & $1333 / 2217(60.1)$ & 623/1739 (35.8) & $1.68(1.50-1.88)$ & $<0.0001$ \\
\hline Beta-lactams & 2244/5622 (39.9) & 2166/6342 (34.2) & $0.86(0.80-0.92)$ & $<0.0001$ \\
\hline \multicolumn{5}{|l|}{ B. Beta-lactams classes } \\
\hline Aminopenicillins & $846 / 1117(75.7)$ & $311 / 440(70.7)$ & $1.07(0.90-1.27)$ & 0.427 \\
\hline Carbapenems & 2/659 (0.3) & $5 / 689(0.7)$ & $0.41(0.8-2.16)$ & 0.298 \\
\hline Monobactams & $77 / 150(51.3)$ & $1 / 204(0.5)$ & $104.7(14.4-761.4)$ & $<0.0001$ \\
\hline Beta-lactam+Inhibitors & 273/754 (36.2) & $331 / 796(41.6)$ & $0.87(0.72-1.05)$ & 0.150 \\
\hline Cephalosporins & 1046/2942 (35.6) & $1518 / 4213(36.0)$ & $1.01(0.93-1.11)$ & 0.776 \\
\hline \multicolumn{5}{|l|}{ C. Cephalosporins classes } \\
\hline $1 \mathrm{GCs}$ & 210/491 (42.8) & 160/462 (34.6) & $1.24(0.97-1.57)$ & 0.087 \\
\hline $2 \mathrm{GCs}$ & $118 / 518(22.8)$ & 375/894 (41.9) & $0.54(0.43-0.69)$ & $<0.0001$ \\
\hline $3 \mathrm{GCs}$ & $571 / 1648(34.7)$ & $850 / 2190(38.8)$ & $0.89(0.89-1.01)$ & 0.072 \\
\hline $4 \mathrm{GCs}$ & 147/285 (51.6) & 133/667 (19.9) & $2.59(1.97-3.40)$ & $<0.0001$ \\
\hline \multicolumn{5}{|c|}{ D. Virulence factors groups } \\
\hline Adhesins & $1635 / 3309(49.4)$ & $681 / 1739(39.2)$ & $1.3(1.13-1.40)$ & $<0.0001$ \\
\hline Siderophore systems & $276 / 428(64.5)$ & $371 / 1121(33.1)$ & $1.9(1.61-2.36)$ & $<0.0001$ \\
\hline Toxins & $312 / 1418(22.0)$ & 217/1246 (17.4) & $1.3(1.05-1.53)$ & 0.016 \\
\hline Immune suppressors & $200 / 276(72.5)$ & $674 / 1339(50.3)$ & $1.4(1.17-1.77)$ & 0.001 \\
\hline
\end{tabular}

lactamase (ESBL) producing E. coli are emerging and are posing challenges to the clinicians on therapeutic choices; and F-plasmids often encode for ESBL genes from the CTX-M, TEM or SHV groups, as well as genes conferring resistance to other antibiotic groups [40-43]. These few examples demonstrate how antimicrobial pressure can select for plasmids carrying virulence and resistance determinants, and hence allow virulent traits to be selected for by antimicrobial use in a bacterial population.

Some specific lineages within the E. coli species, such as the phylogroup B2, show high frequency of virulence factors [44-46]. Independent predictors for pathogenicity have been identified to be alphahemolysin, yersiniabactin receptor $(f y u A)$, serum resistance-associated outer membrane protein $(\operatorname{traT})$, and aerobactin receptor type iutA. In strains producing the $b l a_{\mathrm{CTX}-\mathrm{M}-1}$ and $b l a_{\mathrm{CTX}-\mathrm{M}-9}$ group ESBL enzymes, respectively, iutA and $\operatorname{tra} T$ were significantly more common among these virulence factors [47]. Similar results, where iut and traT are more prevalent, have been reported in E. coli CTX-M ESBL group from UTIs [48].

\section{Discussion}

Uropathogenic Escherichia coli (UPEC) are the primary bacterial type associated with urinary tract infection (UTI) [1]. They include diverse E. coli phylogroups that express a wide range of virulence factors and genes that can increase its pathogenicity and resistance to antimicrobials [4, 49-52]. During the last few decades, the emergence of high rates of antimicrobial resistance and multidrug resistance (MDR) phenotype reported in UPEC has become a major concern worldwide [53, 54]. In this study, we reported virulence factors and antimicrobial resistance of UPEC.

The study of AMR showed variable proportions of resistance in different antimicrobial categories. High resistance rates were observed in aminopencillins, tetracyclins, cotrimoxazole, nalidixic acid and cephalopsporins. Several studies have reported high resistance rates of UPEC on these antibiotics and by different mechanisms $[52,53,55,56]$. This study showed high resistance to beta-lactam antibiotics. The increasing rate of 3rdgeneration cephalosporin resistance, suggesting extended-spectrum beta-lactamase (ESBL) producing $E$. coli is of concern worldwide. It has been reported that 
carbapenems are the best options for treating ESBL UPEC-producers [1, 57], and our findings report similar results with susceptibility rates to carbapenems close to $100 \%$. However, there is high risk of a similar development like the spread of ESBL following the widespread use of 3rd generation cephalosporins; the spread of carbapenem resistance mechanisms if these are used routinely. Using carbapenems as first-line antimicrobial treatment does not make them the best option as first line over oral agents like nitrofurantoin and/or fosfomycin in treating UTIs, and reserving carbapenem use for extensively drug resistant isolates with few or no other treatment alternatives.

Regarding virulence factors of UPEC, this study showed a high prevalence of fimbriae (fimH/MSHA: 75\%). P fimbriae and type 1 fimbriae are known to play a key role in the pathogenesis by facilitating the attachment of E. coli to the uroepithelium [58]. The fimH adhesion mediates the adherence of UPEC to the bladder epithelium as well as the invasion of bladder epithelial and mast cells into caveolae, which has been reported to protect the bacteria from host defences and antimicrobials [59]. In addition to that, the P-fimbrial adhesins, encoded by the pap $G$ gene, mediate the attachment to the P-blood group antigens on uroepithelial cells [59]. The expression of E. coli surface adhesins is increased by initiating the close contact of the bacteria with the host cell wall. Receptors for S- and P-fimbriae are located, in UPEC pathotypes, on the surface of epithelial cells lining the host urinary tract [10], and the high hydrophobicity of bacterial cell promotes the adherence of UPEC to mucosal epithelial cells surfaces [60]. UPEC pathotypes carry significantly higher numbers of fimbrial gene clusters compared to faecal/commensal pathotypes [61]. Siderophores bind ferric iron and iron-siderophore complexes are recognised by cognate outer-membrane receptors. UPEC pathotypes encode the proteins required for the biosynthesis and uptake of several siderophores, such as enterobactin, aerobactin, yersiniabactin and salmochelin [61]. Haemolysin and siderophores are secreted virulence factors that enable the UPEC to colonize the urinary tract and persist despite the effectively functioning host immune defence mechanism [53]. The iron uptake systems of UPEC are mediated by the siderophore aerobactin synthesized by a number of iuc genes and proteins encoded by iut genes mediate its transport $[62,63]$. This study showed prevalence of $i u c D$ and iutA genes of 66 and $62 \%$, respectively. The toxins produced by UPEC inflict tissue damage and are involved in the host-pathogen interplay [61]. This is mediated by the haemolysin $(h l y A)$, in addition to its cytolytic effect. The $h l y A$ was the most reported toxin in this review, followed by sat and cnf-1. The cnf-1 help the UPEC to survive even in the presence of neutrophils [61]. However, the invasins like the $\operatorname{sis} A$ and $\operatorname{sis} B$ play a key role in suppressing the host immune response during the initial stages of infection [64]. The summary of UPEC virulence factors mechanisms is in Table 5.

Table 5 UPEC virulence factors mechanisms of action

\begin{tabular}{|c|c|c|}
\hline $\begin{array}{l}\text { Virulence } \\
\text { factors groups }\end{array}$ & Examples of genes & Mechanisms \\
\hline Adhesins & $\begin{array}{l}\text { afa, CSH, fimH, fimP, } \\
\text { kpsmtll, pap, sfa, traT }\end{array}$ & $\begin{array}{l}\text { UPEC adhesins can contribute to virulence in different ways: (i) directly triggering host and bacterial } \\
\text { cell signalling pathways, (ii) facilitating the delivery of other bacterial products to host tissues, and } \\
\text { (iii) promoting bacterial invasion [3]. Adhesins help in the adhesion of organism to epithelial cell } \\
\text { surface, thereby it escapes from flushing action during micturition [7]. Fimbriae is responsible for } \\
\text { adhesion, colonization, invasion of host epithelium and makes UPEC to escape from the innate } \\
\text { immune system by internalization process within urothelial cells which is mediated by the } \\
\text { transduction cascades [8]. }\end{array}$ \\
\hline Toxins & Cnfl, hlyA, sat, vat & $\begin{array}{l}\text { Toxins like haemolysin and Cytotoxic Necrotising Factor (CNF) act by their cytotoxicity and } \\
\text { invasiveness. Haemolysin production could inhibit the cytokine production of host cells and } \\
\text { promote the cytotoxicity. It causes lysis of the erythrocytes which release nutrients and other } \\
\text { vitamins available for the bacteria. At the same time it releases inflammatory mediators and } \\
\text { enzymes which are cytotoxic to renal proximal tubular epithelial cells, erythrocytes and leukocytes, } \\
\text { thereby causing renal epithelial damage [3]. CNF interferes with the phagocytosis of E. coli by the } \\
\text { WBCs and thus it leads to exfoliation and apoptosis of bladder epithelial cells. It further enhances } \\
\text { the easy access of bacteria into the underlying tissue. These toxins can alter signalling pathways, } \\
\text { provoke the inflammatory response and prevent the apoptosis thereby they cause the UPEC } \\
\text { population to expand [1]. }\end{array}$ \\
\hline
\end{tabular}

Siderophores aer, chuA, fyuA, iuD, iutA, $y f C v$

Immune $\quad P A l$, shiA, sisA, sisB, sivH, suppressors ECO274
Production of siderophores by E. coli which takes up iron from the host and helps in colonization and survival of pathogen $[1,8]$. They contribute to the process of nutritional passivation of metal ions, in which UPEC access these vital nutrients while simultaneously protecting themselves from their toxic potential [65]

UPEC induces a non-sterilizing adaptive immune response in the bladder. Its causes long-lasting changes in the bladder urothelium, conferring resistance or increased susceptibility to subsequent infections depending on the outcomes of the first infection [66]. The invasins play a key role in suppressing the host immune response during the initial stages of infection [64]. 
Virulence factors and antimicrobial resistance patterns of UPEC is varying from a region to another. A local and/or national antimicrobial resistance and UPEC virulence factors study may be useful for staying abreast regarding the trend for the UTIs' empirical treatment [9]. Intervention strategies on virulence factors that govern the UPEC-mediated UTIs symptomatology may protect against a wide range of UTI syndromes.

\section{Conclusion}

Relative high rates in antimicrobial resistance were observed among aminopenicillins, beta-lactams associated with inhibitors, tetracyclines, sulfonamides, quinolones and 1st generation cephalosporins. This suggests a reassessment of empirical therapies in urinary tract infections treatment caused by this pathogen. The most frequent observed virulence factors included both surface and secreted virulence factors (shiA, CSH, fimH/ MSHA, traT, sisA, iucD, iutA, kpsMTII, and PAI).

\section{Abbreviations}

UPEC: Uropathogenic Escherichia coli; AMR: Antimicrobial resistance; UTI: Urinary tract infection; MGE: Mobile genetic elements; ExPEC: Extraintestinal pathogenic E. coli; PAls: Pathogenicity islands; MDR: Multidrug resistance; PRISMA: Preferred reporting items for systematic reviews and meta-analyses; NOS: Newcastle-Ottawa Scale; ESBL: Extended-spectrum betalactamase

\section{Supplementary Information}

The online version contains supplementary material available at https://doi. org/10.1186/s12879-021-06435-7

Additional file 1. Newcastle-Ottawa Scale adapted for cross-sectional studies.

Additional file 2: Table S1. Studies assessment using the NewcastleOttawa Scale adapted for assessment of cross-sectional studies.

\begin{abstract}
Authors' contributions
GKB: conception and design, acquisition, extraction, analysis and interpretation of data, drafting and revision of the manuscript. VSP: analysis and interpretation of data. JM: conception and design, acquisition, extraction and interpretation of data. PN: Literature search. NF, EH, JM: critically revised the manuscript for its scientific contents. All authors read and approved the final manuscript.
\end{abstract}

\section{Funding}

Authors are thankful to the Africa Centre of Excellence in Public Health and Herbal Medicine (ACEPHEM) and the Malawi-Liverpool-Wellcome Trust (MLW) training core funding (Wellcome Trust award 206545/Z/17/Z). The funding bodies had no role in the study design, data collection, analysis and interpretation of results, writing the manuscript or decision to publish this paper.

\section{Availability of data and materials}

All data generated or analysed during this study are included in this published article.

\section{Declarations}

Ethics approval and consent to participate Not applicable.
Consent for publication

Not applicable.

\section{Competing interests}

The authors declare that they have no competing interests.

\section{Author details}

${ }^{1}$ Department of Pathology, Kamuzu University of Health Sciences (former College of Medicine/University of Malawi), Blantyre, Malawi. ${ }^{2}$ Africa Centre of Excellence in Public Health and Herbal Medicine (ACEPHEM), Blantyre, Malawi. ${ }^{3}$ Malawi-Liverpool-Wellcome Trust Clinical Research Programme, Blantyre, Malawi. ${ }^{4}$ Department of Infectious Diseases, Faculty of Medicine, Université Catholique du Graben, Butembo, Democratic Republic of the Congo. ${ }^{5}$ Liverpool School of Tropical Medicine, Pembroke Place, Liverpool L3 5QA, UK. ${ }^{6}$ Department of Public Health, Kamuzu University of Health Sciences (former College of Medicine/University of Malawi), Blantyre, Malawi. ${ }^{7}$ Department of Surgery, Queen Elizabeth Central Hospital, Blantyre, Malawi.

Received: 10 March 2021 Accepted: 13 July 2021

Published online: 04 August 2021

\section{References}

1. Terlizzi ME, Gribaudo G, Maffei ME. UroPathogenic Escherichia coli (UPEC) infections : virulence factors, bladder responses, antibiotic and nonantibiotic antimicrobial strategies. Front Microbiol. 2017;8:1566. https://doi. org/10.3389/fmicb.2017.01566.

2. Raeispour M, Ranjbar R. Antibiotic resistance, virulence factors and genotyping of Uropathogenic Escherichia coli strains. Antimicrob Resist Infect Control. 2018;7(1):118. https://doi.org/10.1186/s13756-018-0411-4.

3. Bien J, Sokolova O, Bozko P. Role of uropathogenic Escherichia coli virulence factors in development of urinary tract infection and kidney damage. Int J Nephrol. 2012:681473. https://doi.org/10.1155/2012/687473.

4. Calhau V, Domingues S, Mendonc N, Jorge G, Silva D, Jorge G, et al. Interplay between pathogenicity island carriage, resistance profile and plasmid acquisition in uropathogenic Escherichia coli. J Med Microbiol. 2015; 64(8):828-35. https://doi.org/10.1099/jmm.0.000104.

5. Partridge SR, Kwong SM, Firth N, Jensen SO. Mobile genetic elements associated with antimicrobial resistance. Clin Microbiol Rev. 2018;31(4) e00088-17.

6. Yan F, Polk DB. Commensal bacteria in the gut: learning who our friends are. Curr Opin Gastroenterol. 2004;20(6):565-71. https://doi.org/10.1097/ 00001574-200411000-00011.

7. Kaper JB, Nataro JP, Mobley HLT. Pathogenic Escherichia coli. Nat Rev Microbiol. 2004;2(2):123-40. https://doi.org/10.1038/nrmicro818.

8. Flores-Mireles AL, Walker JN, Caparon M, Hultgren SJ. Urinary tract infections: epidemiology, mechanisms of infection and treatment options. Nat Rev Microbiol. 2015;13(5):269-84. https://doi.org/10.1038/nrmicro3432.

9. Düzgün AÖ, Okumuş F, Saral A, Çiçek AÇ, Cinemre S. Determination of antibiotic resistance genes and virulence factors in Escherichia coli isolated from Turkish patients with urinary tract infection. Rev Soc Bras Med Trop. 2019;52:e20180499. https://doi.org/10.1590/0037-8682-0499-2018.

10. Sarowska J, Futoma-Koloch B, Jama-Kmiecik A, Frej-Madrzak M, Ksiazczyk M, Bugla-Ploskonska $\mathrm{G}$, et al. Virulence factors, prevalence and potential transmission of extraintestinal pathogenic Escherichia coli isolated from different sources: recent reports. Gut Pathog. 2019;11(1):10. https://doi.org/1 0.1186/s13099-019-0290-0.

11. Ikram R, Psutka R, Carter A, Priest P. An outbreak of multi-drug resistant Escherichia coli urinary tract infection in an elderly population: a casecontrol study of risk factors. BMC Infect Dis. 2015;15(1):224. https://doi.org/1 0.1186/s12879-015-0974-0.

12. Lee DS, Lee SJ, Choe HS, Giacobbe DR. Community-acquired urinary tract infection by Escherichia coli in the era of antibiotic resistance. Biomed Res Int. 2018:7656752. https://doi.org/10.1155/2018/7656752.

13. Alanazi $M Q$, Alqahtani FY, Aleanizy FS. An evaluation of E. coli in urinary tract infection in emergency department at KAMC in Riyadh, Saudi Arabia: retrospective study. Ann Clin Microbiol Antimicrob. 2018;17(1):3. https://doi. org/10.1186/s12941-018-0255-z.

14. O'Neill J. Tackling drug-reistant infections globally: final report and recommendations. In: The review on antimicrobial resistance; 2016. 
15. Moher D, Liberati A, Tetzlaff J, Altman DG, Prisma-Group. Preferred reporting items for systematic reviews and meta-analyses: The PRISMA statement. Plos Med. 2009;6(7):e1000097.

16. O'Brien VP, Dorsey DA, Hannan TJ, Hultgren SJ. Host restriction of Escherichia coli recurrent urinary tract infection occurs in a bacterial strainspecific manner. PLoS Pathoges. 2018;14(12):e1007457. https://doi.org/10.13 71/journal.ppat.1007457.

17. Centers for Disease Control and Prevention. Urinary Tract Infection (Catheter-Associated Urinary Tract Infection [CAUTI] and Non-CatheterAssociated Urinary Tract Infection [ UTI ]) Events. 2020 [cited 2020 Feb 20]. Available from: http://www.cdc.gov/nhsn/PDFs/pscManual/7pscCA UTIcurrent.pdf

18. Nyaga VN, Arbyn M, Aerts M. Metaprop: a Stata command to perform metaanalysis of binomial data. Arch Public Health. 2014;72(1):39. https://doi.org/1 0.1186/2049-3258-72-39.

19. Hunter JP, Saratzis A, Sutton AJ, Boucher RH, Sayers RD, Bown MH. In metaanalyses of proportion studies, funnel plots were found to be an inaccurate method of assessing publication bias. J Clin Epidemiol. 2014;67(8):897-903. https://doi.org/10.1016/j.jclinepi.2014.03.003.

20. Ghazvini H, Taheri K, Edalati E, Sedighi M, Mirkalantari S. Virulence factors and antimicrobial resistance in uropathogenic Escherichia coli strains isolated from cystitis and pyelonephritis. Turkish J Med Sci. 2019;49(1):361-7. https://doi.org/10.3906/sag-1805-100.

21. Jadhav S, Hussain A, Devi S, Kumar A, Parveen S, Gandham N, et al. Virulence characteristics and genetic affinities of multiple drug resistant uropathogenic Escherichia coli from a semi urban locality in India. PLoS One. 2011;6(3):e78063.

22. Kot B, Wicha J, Grużewska A, Piechota M, Wolska K, Obrębska M. Virulence factors, biofilm-forming ability, and antimicrobial resistance of urinary Escherichia coli strains isolated from hospitalized patients. Turkish J Med Sci. 2016;46(6):1908-14. https://doi.org/10.3906/sag-1508-105.

23. Malekzadegan Y, Khashei R, Sedigh Ebrahim-Saraie H, Jahanabadi Z. Distribution of virulence genes and their association with antimicrobial resistance among uropathogenic Escherichia coli isolates from Iranian patients. BMC Infect Dis. 2018;18(1):572. https://doi.org/10.1186/s12879-018-3467-0.

24. Miranda-Estrada LI, Ruíz-Rosas M, Molina-López J, Parra-Rojas I, GonzálezVillalobos E, Castro-Alarcón N. Relationship between virulence factors, resistance to antibiotics and phylogenetic groups of uropathogenic Escherichia coli in two locations in Mexico. Enferm Infecc Microbiol Clin. 2017;35(7):426-33. https://doi.org/10.1016/j.eimc.2016.02.021.

25. Neamati F, Firoozeh F, Saffari M, Zibaei M. Virulence genes and antimicrobial resistance pattern in Uropathogenic Escherichia coli isolated from hospitalized patients in Kashan, Iran. Jundishapur J Microbiol. 2015;8(2): e17514. https://doi.org/10.5812/jjm.17514

26. Oliveira FA, Paludo KS, Arend LNVS, Farah SMSS, Pedrosa FO, Souza EM, et al. Virulence characteristics and antimicrobial susceptibility of uropathogenic Escherichia coli strains. Genet Mol Res. 2011;10(4):4114-25. https://doi.org/10.4238/2011.October.31.5.

27. Olorunmola FO, Kolawole DO, Lamikanra A. Antibiotic resistance and virulence properties in escherichia coli strains from cases of urinary tract infections. Afr J Infect Dis. 2013;7(1):1-7. https://doi.org/10.4314/ajid.v7i1.1.

28. Shakhatreh MAK, Swedan SF, Al-Odat MA, Khabour OF. Uropathogenic Escherichia coli (UPEC) in Jordan: prevalence of urovirulence genes and antibiotic resistance. J King Saud Univ Sci. 2019;31(4):648-52. https://doi. org/10.1016/j.jksus.2018.03.009.

29. Tabasi M, Asadi Karam MR, Habibi M, Yekaninejad MS, Bouzari S. Phenotypic assays to determine virulence factors of Uropathogenic Escherichia coli (UPEC) isolates and their correlation with antibiotic resistance pattern. Osong Public Heal Res Perspect. 2015;6(4):261-8. https://doi.org/10.1016/j. phrp.2015.08.002.

30. Wang Y, Zhao S, Han L, Guo X, Chen M, Ni Y, et al. Drug resistance and virulence of uropathogenic Escherichia coli from Shanghai, China. J Antibiot (Tokyo). 2014;67(12):799-805. https://doi.org/10.1038/ja.2014.72.

31. Velasco M, Horcajada JP, Moreno-martinez A, Vila J, Martinez A, Ruiz J, et al. Decreased invasive capacity of quinolone-resistant Escherichia coli in patients with urinary tract infections. Clin Infect Dis. 2001;33(10):1682-386. https://doi.org/10.1086/323810.

32. Hacker J, Blum-Oehler G, Muhldorfer I, Tschape H. Pathogenicity islands of virulent bacteria: structure, function and impact on microbial evolution. Mol Microbiol. 1997;23(6):1089-97. https://doi.org/10.1046/j.1365-2958.1997.3101 672.x
33. Vila J, Simon K, Ruiz J, Horcajada JP, Velasco M, Barranco M, et al. Are quinolone-resistant uropathogenic Escherichia coli less virulent? J Infect Dis. 2002;186(7):1039-42. https://doi.org/10.1086/342955.

34. Chung The H, Boinett C, Pham Thanh D, Jenkins C, Weill FX, Howden BP, et al. Dissecting the molecular evolution of fluoroquinolone-resistant Shigella sonnei. Nat Commun. 2019;10(1):4828. https://doi.org/10.1038/s414 67-019-12823-0

35. Fortie L-C, Sekulovic O. Importance of prophages to evolution and virulence of bacterial pathogens. Virulence. 2013;4(5):354-65. https://doi.org/10.4161/ viru. 24498.

36. Soto SM, De Anta MTJ, Vila J. Quinolones induce partial or total loss of pathogenicity islands in uropathogenic Escherichia coli bt SOS-dependant or -independant pathways, respectively. Antimicrob Agents Chemother. 2006;50(2):649-53. https://doi.org/10.1128/AAC.50.2.649-653.2006.

37. Johnson TJ, Nolan LK. Pathogenomics of the virulence plasmids of Escherichia coli. Microbiol Mol Biol Rev. 2009;73(4):750-74. https://doi.org/1 0.1128/MMBR.00015-09.

38. Villa L, García-Fernández A, Fortini D, Carattoli A. Replicon sequence typing of IncF plasmids carrying virulence and resistance determinants. J Antimicrob Chemother. 2010;65(12):2518-29. https://doi.org/10.1093/jac/dkq347.

39. da Silva GJ, Mendonça N. Association between antimicrobial resistance and virulence in Escherichia coli. Virulence. 2012;3(1):18-28. https://doi.org/10.41 61/viru.3.1.18382.

40. Martínez JL, Baquero F. Interactions among strategies associated with bacterial infection: pathogenicity, Epidemicity, and antibiotic resistance. Clin Microbiol Rev. 2002;15(4):647-79. https://doi.org/10.1128/CMR.15.4.647-679.2002.

41. Garcillán-Barcia MP, de la Cruz F. Why is entry exclusion an essential feature of conjugative plasmids? Plasmid. 2008;60(1):1-18. https://doi.org/10.1016/j. plasmid.2008.03.002.

42. Szczepanowski R, Braun S, Riedel V, Schneiker S, Krahn I, Pühler A, et al. The 120592 bp IncF plasmid pRSB107 isolated from a sewage-treatment plant encodes nine different antibiotic-resistance determinants, two ironacquisition systems and other putative virulence-associated functions. Microbiology. 2005;154(4):1095-111.

43. Carattoli A. Resistance plasmid families in Enterobacteriaceae. Antimicrob Agents Chemother. 2009;53(6):2227-38. https://doi.org/10.1128/AAC.01707-08.

44. Pitout JD, Laupland KB, Church DL, Menard ML, Johnson JR. Virulence factors of Escherichia coli isolates that produce CTX-M-type extendedspectrum beta-lactamases. Antimicrob Agents Chemother. 2005;49(11): 4667-70. https://doi.org/10.1128/AAC.49.11.4667-4670.2005.

45. Karisik E, Ellington MJ, Livermore DM, Woodford N. Virulence factors in Escherichia coli with CTX-M-15 and other extended-spectrum betalactamases in the UK. J Antimicrob Chemother. 2008;61(1):54-8. https://doi. org/10.1093/jac/dkm401.

46. Johnson JR, Goullet P, Picard B, Moseley SL, Roberts PL, Stamm WE. Association of carboxylesterase B electrophoretic pattern with presence and expression of urovirulence factor determinants and antimicrobial resistance among strains of Escherichia coli that cause urosepsis. Infect Immun. 1991; 59(7):2311-5. https://doi.org/10.1128/iai.59.7.2311-2315.1991.

47. Lee S, Yu JK, Park K, Oh E-J, Kim S-Y, Park Y-J. Phylogenetic groups and virulence factors in pathogenic and commensal strains of Escherichia coli and their association with blaCTX-M. Ann Clin Lab Sci. 2010;40(4):361-7.

48. Lavigne J-P, Blanc-Potard A-B, Bourg G, Moreau J, Chanal C, Bouziges N, et al. Virulence genotype and nematode-killing properties of extra-intestinal Escherichia coli producing CTX-M beta-lactamases. Clin Microbiol Infect. 2006;12(12):1199-206. https://doi.org/10.1111/j.1469-0691.2006.01536.x.

49. Peerayeh SN, Navidinia M, Fallah F, Bakhshi B, Jamali J. Pathogenicity determinants and epidemiology of uropathogenic E . coli ( UPEC) strains isolated from children with urinary tract infection ( UTI ) to define distinct pathotypes. Biomed Res. 2018;29(10):2035-43.

50. Slavchev G, Pisareva E, Markova N. Virulence of uropathogenic Escherichia coli. J Cult Collect. 2009;6(2008-2009):3-9.

51. Beceiro A, Tomás M, Bou G. Antimicrobial resistance and virulence : a successful or deleterious Association in the Bacterial World ? Clin Microbiol Rev. 2013;26(2):185-230. https://doi.org/10.1128/CMR.00059-12.

52. Geisinger $\mathrm{E}$, Isberg RR. Interplay between antibiotic resistance and virulence during disease promoted by multidrug-resistant Bacteria. J Infect Dis. 2017; 215(Suppl 1):9-17.

53. Shah C, Baral R, Bartaula B, Shrestha LB. Virulence factors of uropathogenic Escherichia coli ( UPEC) and correlation with antimicrobial resistance. BMC Microbiol. 2019;19(1):204. https://doi.org/10.1186/s12866-019-1587-3. 
54. Ramírez-Castillo FY, Moreno-Flores AC, Avelar-González FJ, Márquez-Díaz F, Harel J, Guerrero-Barrera AL. An evaluation of multidrug - resistant Escherichia coli isolates in urinary tract infections from Aguascalientes, Mexico: cross - sectional study. Ann Clin Microbiol Antimicrob. 2018:17:34.

55. Miranda-estrada LI, Ruíz-rosas M, Molina-lópez J, Parra-rojas I, GonzalezVillalobos E, Castro-Alarcon N. Relationship between virulence factors, resistance to antibiotics and phylogenetic groups of uropathogenic Escherichia coli in two locations. Enferm Infecc Microbiol Clin. 2017;35(7): 426-33. https://doi.org/10.1016/j.eimc.2016.02.021.

56. Irenge LM, Ambroise J, Bearzatto B, Durant J, Chirimwami RB, Gala J-L. Whole-genome sequences of multidrug- resistant Escherichia coli in SouthKivu Province, Democratic Republic of Congo: characterization of phylogenomic changes, virulence and resistance genes. BMC Infect Dis. 2019;19(1):137. https://doi.org/10.1186/s12879-019-3763-3.

57. Pootong A, Mungkornkeaw N, Norrapong B, Cowawintaweewat S. Phylogenetic background, drug susceptibility and virulence factors of uropathogenic $\mathrm{E}$. coli isolate in a tertiary university hospital in central Thailand. Trop Biomed. 2018;35(1):195-204.

58. Vagarali MA, Karadesai SG, Patil CS, Metgud SC, Mutnal MB. Haemagglutination and siderophore production as the urovirulence markers of uropathogenic Escherichia coli. Indian J Med Microbiol. 2008;26(1):68-70. https://doi.org/10.1016/S0255-0857(21)01997-6.

59. Marrs CF, Zhang L, Foxman B. Escherichia coli mediated urinary tract infections: are there distinct uropathogenic E. coli (UPEC) pathotypes? FEMS Microbiol Lett. 2005;252(2):183-90. https://doi.org/10.1016/j.femsle.2005.08.028.

60. Shruthi N, Ravishkukar R. Phenotypic study of virulence factors in Escherichic coli isolated from antenatal cases, catheterized patients, and faecal flora. J Clin Diagnostic Res. 2012;6(10):1699-703.

61. Subashchandrabose S, Mobley HLT. Virulence and fitness determinants of uropathogenic Escherichia coli. Microbiol Spectr. 2015;3(4):1-20.

62. Torres AG, Redford P, Welch RA, Payne SM. TonB-dependent systems of uropathogenic Escherichia coli: aerobactin and heme transport and TonB are required for virulence in the mouse. Infect Immun. 2001;69(10):6179-85. https://doi.org/10.1128//Al.69.10.6179-6185.2001.

63. Marrs CF, Zhang L, Tallman P, Manning S, Somsel P, Raz R, et al. Variations in 10 putative virulence genes among urinary, faecal and peri-urethral Escherichia coli. J Med Microbiol. 2002;51(2):138-42. https://doi.org/10.1099/ 0022-1317-51-2-138.

64. Lloyd AL, Smith SN, Eaton KA, Mobley HLT. Uropathogenic Escherichia coli suppresses the host inflammatory response via Pathogenicity Island genes sisA and sisB. Infect Immun. 2009;77(12):5322-33. https://doi.org/10.1128/IAI. 00779-09.

65. Su Q, Guan T, Lv H. Siderophore biosynthesis coordinately modulated the virulence-associated interactive metabolome of uropathogenic Escherichia coli and human urin. Sci Rep. 2016;6(1):24099. https://doi.org/10.1038/srep24099.

66. Mariano LL, Ingersoll MA. The immune response to infection in the bladder Nat Rev Urol. 2020;17(8):439-58. https://doi.org/10.1038/s41585-020-0350-8.

\section{Publisher's Note}

Springer Nature remains neutral with regard to jurisdictional claims in published maps and institutional affiliations.

Ready to submit your research? Choose BMC and benefit from:
- fast, convenient online submission
- thorough peer review by experienced researchers in your field
- rapid publication on acceptance
- support for research data, including large and complex data types
- gold Open Access which fosters wider collaboration and increased citations
- maximum visibility for your research: over 100M website views per year
At BMC, research is always in progress.
Learn more biomedcentral.com/submissions

